\title{
PIOMETRA EM PORQUINHO DA ÍNDIA (Cavia porcellus)-RELATO DE CASO
}

\author{
BRUSTOLIN, Joice Magali ${ }^{1}$; \\ WEILLER, Maria Amélia Agnes ${ }^{2}$; \\ SOUZA, Camila Lopes de ${ }^{3}$; \\ BRITO, Harald Fernando Vicente de ${ }^{4}$; \\ VOGEL, Fernanda Silveira Flôres ${ }^{5}$; \\ BOTTON, Sônia de Avila ${ }^{5}$; \\ SANGIONI, Luís Antônio ${ }^{5}$.
}

\section{RESUMO}

$P$ iometra é um processo inflamatório do útero caracterizado pelo acúmulo de secreção purulenta no lúmen uterino associado a uma infecção bacteriana. Pode se apresentar de duas formas, com cérvix aberta ou fechada, sendo esta última considerada como uma urgência veterinária pelo risco de vida para o paciente. $O$ tratamento desta patologia pode ser cirúrgico, através da técnica de ovariosalpingohisterectomia (OSH), ou medicamentoso, devendo sempre ser observado o estado geral do paciente para a correta escolha do tratamento. A ultrassonografia é o exame diagnóstico mais utilizado para esta enfermidade, sendo considerado o de eleição para esta afeç̧ão por diversos autores. Este artigo teve como objetivo relatar um caso clínico de piometra de cérvix fechada em uma porquinha da índia (Cavia porcellus). O animal foi submetido ao exame ultrassonográfico devido ao aumento de volume na cavidade abdominal, vindo a óbito durante o procedimento. Não foram observadas alterações fisiológicas e hematológicas. Procedeu-se a realização de exame necroscópico, sendo diagnosticada como causa do óbito a ruptura uterina. Foi constatada a liberação de exsudato purulento proveniente do útero e cornos uterinos para a cavidade abdominal. Concluiu-se que a causa do óbito do animal foi devido à ruptura uterina, com extravasamento do conteúdo uterino na cavidade abdominal, devido a uma piometra na forma de cérvix fechada.

Palavras-chave: Piometra. Cérvix fechada. Cobaio. Infecção uterina. 


\section{INTRODUÇÃO}

Piometra é um processo inflamatório do útero, com acúmulo de secreção purulenta associada a uma infecção bacteriana secundária, devido à influência hormonal, na qual há uma resposta exagerada do endométrio à progesterona, predispondo às infecções bacterianas (JONES et al., 2007; WEISS et al., 2004).

A doença pode apresentar-se de duas formas: com cérvix aberta ou fechada, sendo esta ultima considerada como uma urgência veterinária (SMITH, 2006) podendo levar à ruptura uterina (CHEN et al., 2007; EVANGELISTA et al., 2011).

A decisão de tratar a piometra cirurgicamente ou clinicamente depende da condição do animal no momento da apresentação, sua idade e a importância de preservar ou não a capacidade reprodutiva do animal (BIRCHARD; SHERDING, 2003). O tratamento cirúrgico é a ovariosalpingohisterectomia (OSH), sendo indicada quando a piometra é de cérvix fechada, ou quando condição clínica do paciente envolva risco de vida (FIENI, 2006).

O tratamento medicamentoso está indicado nos casos de piometra aberta, em fêmeas jovens, ou quando estas se apresentarem em bom estado geral de saúde (JEFFCOATE, 1999), podendo perdurar por um período de até quatro semanas (FIENI, 2006).

Porquinhos da Índia (Cavia porcellus) pertencem a classe Mammalia, ordem Rodentia (STORER et al., 1998), e dentre as finalidades de sua criação estão o emprego como cobaios em pesquisas científicas, na produção de carne e como animais de companhia (pet) (VALIM et al., 2004).

Enquanto a popularidade dos pequenos mamíferos aumenta, o mesmo acontece com a necessidade de cuidados médicos mais avançados, testes de diagnóstico e procedimentos cirúrgicos específicos (MIRANDA et al., 2011). A maioria das pesquisas relatadas em pequenos roedores está fundamentada nos trabalhos realizados em laboratório, sendo frequentemente baseadas em diagnósticos post-mortem (MARKOVITS; SAHOTA, 2000).

Desordens reprodutivas acometendo esta espécie, como cistos ovarianos, foram descritas por diversos autores (BENNETT, 2012; BURNS et al., 2001; SCHUETZENHOFER et al., 2011; 
SHI et al., 2002). Birchard e Sherding (2003) citam que as descargas vaginais em porquinhas da índia podem resultar em piometra.

O objetivo deste artigo foi descrever um caso clínico de piometra de cérvix fechada em uma porquinha da índia (Cavia porcellus).

\section{RELATO DE CASO}

Uma porquinha da índia (C. porcellus), fêmea, com 800 gramas de peso vivo e aproximadamente dois anos de idade, foi atendida no Núcleo de Ensino e Pesquisa de Animais Selvagens (NEPAS) da Universidade Federal de Santa Maria (UFSM), apresentando sinais de apatia, sem alterações nos parâmetros hematológicos e de temperatura corporal nas últimas quatro semanas que antecederam o atendimento (Tabela 1). Esta fêmea fazia parte de um grupo de porquinhos da índia, todos provenientes de um biotério comercial, os quais se encontravam em período de adaptação a um novo ambiente para posteriormente serem utilizados em um experimento científico na área de doenças parasitárias. Todos os exemplares estavam sendo monitorados diariamente, por um período de quatro semanas, quanto às suas funções fisiológicas e, semanalmente, através de hemograma, visando à seleção dos animais que estariam aptos para serem utilizados no experimento. Todos recebiam água e alimentação à vontade, não estavam sendo submetidos a nenhum protocolo medicamentoso, nem avaliados quanto ao ciclo estral. Algumas fêmeas deram cria durante o período de adaptação. 
Tabela 1 - Avaliações dos parâmetros hematológicos e média da temperatura corporal semanal de uma porquinha da índia (C. porcellus), durante quatro semanas consecutivas.

\begin{tabular}{|c|c|c|c|c|c|}
\hline & 1a semana & 2a semana & 3a semana & 4a semana & $\begin{array}{l}\text { Valores de referência } \\
\text { (WESCHE, 2009) }\end{array}$ \\
\hline \multicolumn{6}{|l|}{ ERITROGRAMA } \\
\hline Hemácias ( $\mu \mathrm{L})$ & 4,53 & 4,20 & 4,81 & 4,76 & $4-7$ \\
\hline Hemoglobina (g/dL) & 11,8 & 11,9 & 11,6 & 11,1 & $11-17$ \\
\hline Hematócrito (\%) & 42,6 & 38,5 & 35,4 & 35,1 & $35-45$ \\
\hline Plaquetas $(/ \mu \mathrm{L})$ & 394.000 & 386.000 & 396.000 & 395.000 & $380.000-650.000$ \\
\hline VCM (fL) & 84,1 & 81,9 & 85,2 & 88,2 & $77,5-88,5$ \\
\hline CHCM (\%) & 29,6 & 29,3 & 29,6 & 30,5 & $28,9-32$ \\
\hline \multicolumn{6}{|l|}{ LEUCOGRAMA } \\
\hline Leucócitos $(/ \mu \mathrm{L})$ & 11.900 & 10.400 & 10.500 & 10.300 & $6.000-14.000$ \\
\hline Segmentados (\%) & 46 & 40 & 57 & 55 & $13-60$ \\
\hline Linfócitos (\%) & 47 & 46 & 33 & 36 & $30-83$ \\
\hline Monócitos (\%) & 02 & 02 & 02 & 02 & $02-20$ \\
\hline Eosinófilos (\%) & 05 & 02 & 03 & 03 & $0-05$ \\
\hline $\begin{array}{l}\text { Temperatura corporal } \\
\text { (Média da semana/ }{ }^{\circ} \mathrm{C} \text { ) }\end{array}$ & $\pm 37,2$ & $\pm 37,4$ & $\pm 37,4$ & $\pm 37,1$ & $37-38,5$ \\
\hline
\end{tabular}

Nesta fêmea atendida, observou-se o aumento da circunferência abdominal durante as quatro semanas do período de adaptação, o que foi sugerido como gestação, visto que havia outras fêmeas nesta mesma condição fisiológica. Ao exame físico, realizado no dia 13 de maio de 2013 , constatou-se normotermia $\left(37^{\circ} \mathrm{C}\right)$. Na palpação abdominal, o animal não manifestava dor, notando-se a presença de líquido na cavidade abdominal, sem apresentar secreção vaginal. A avaliação de ausculta cardíaca e pulmonar não apresentava alterações. Como o animal encontrava-se apático e letárgico, optou-se pela realização do exame ultrassonográfico no Hospital Veterinário da UFSM, quando foi verificada uma distensão uterina com conteúdo ecogênico. Durante o exame ultrassonográfico a paciente foi a óbito.

Posteriormente o animal foi encaminhado para o exame necroscópico, sendo constatada a presença de grande quantidade de líquido purulento (exsudato) de odor fétido e coloração amarelo-clara na cavidade abdominal (Figura 1), proveniente da ruptura uterina, sendo o 
ponto de ruptura possível de ser observado na trompa esquerda. $\mathrm{O}$ exsudato purulento presente no útero e cornos uterinos, era mais abundante na trompa esquerda (Figura 2).

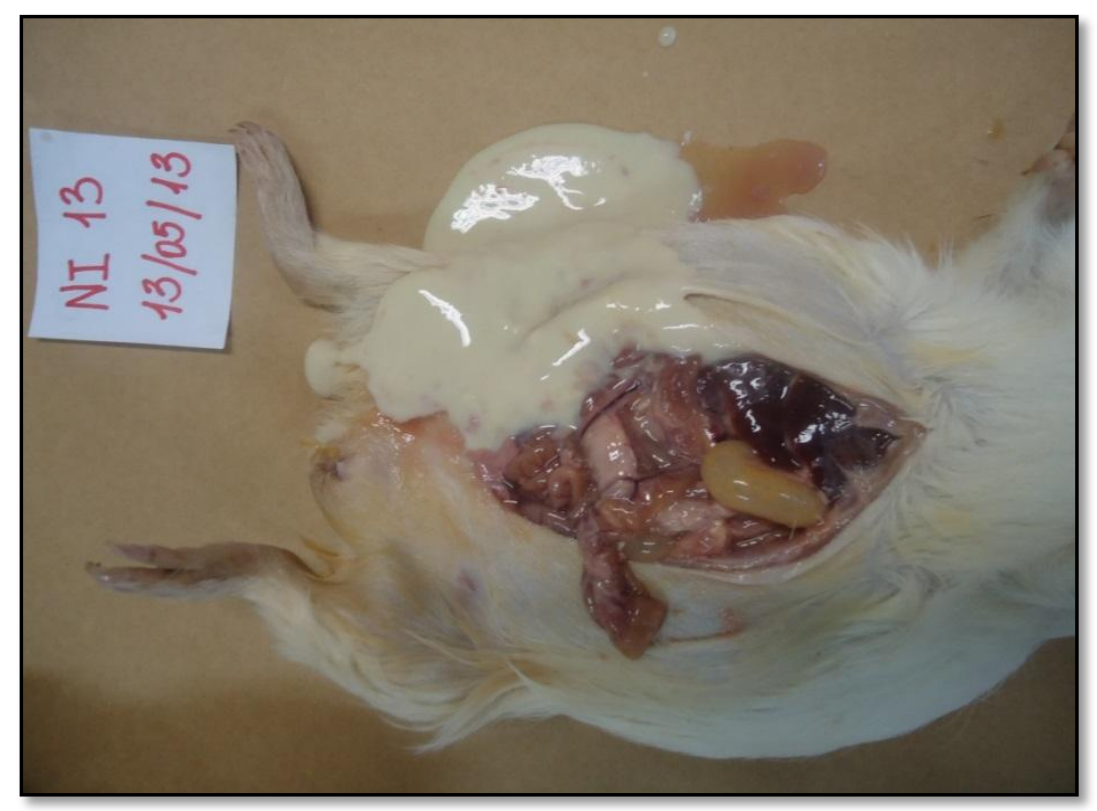

Figura 1 - Presença de exsudato purulento na cavidade abdominal, de odor fétido e coloração amarelo-clara.

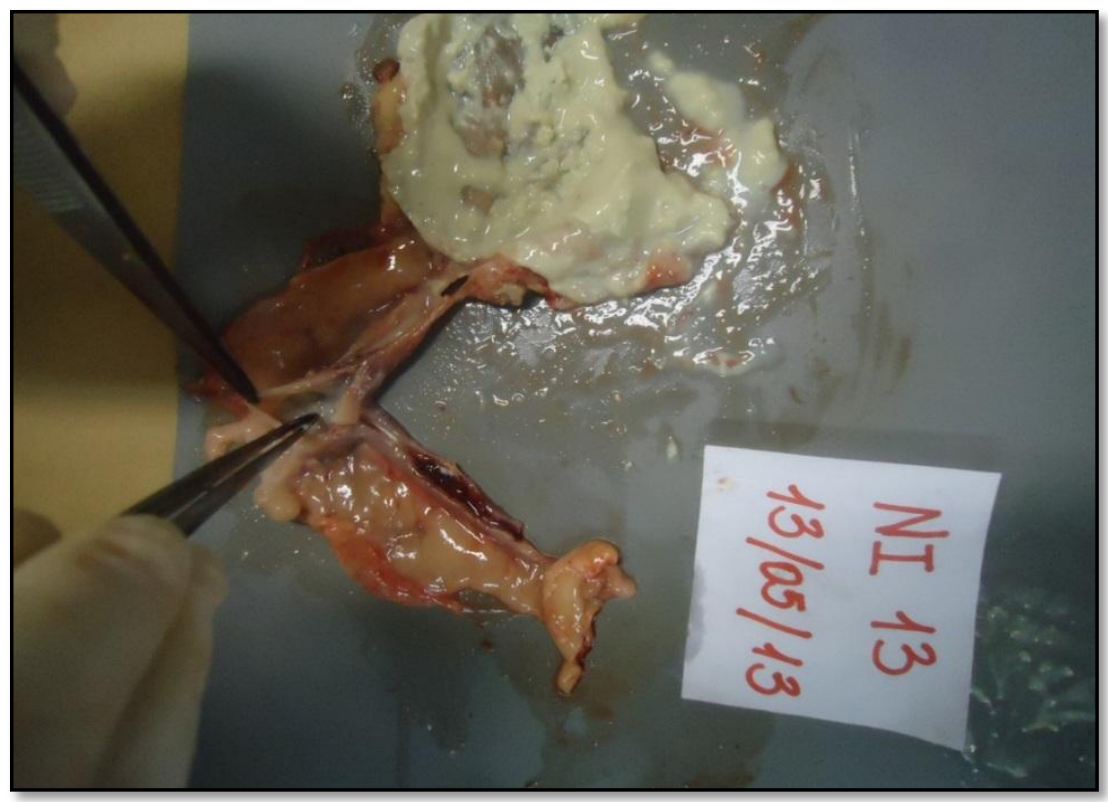

Figura 2 - Cornos uterinos e útero de cobaia com presença de exsudato purulento; nota-se maior presença de conteúdo na tuba uterina esquerda do animal. 


\section{RESULTADOS E DISCUSSÃO}

A piometra trata-se de uma alteração endometrial do útero, sendo correlacionada a altos níveis de estrógeno e exposição prolongada à progesterona (HAGMAN, 2004). O hormônio progesterona estimula a secreção glandular, com supressão da atividade contrátil miometrial, permitindo, dessa forma, o acúmulo de secreções, o que propicia excelente meio para o crescimento bacteriano (GILBERT, 1992). De Bosschere et al. (2001) relatam que as lesões provocadas por piometra resultam da interação hormonal e bacteriana, sendo o desequilíbrio hormonal uma predisposição no desenvolvimento da doença. Acrescentam, ainda, que as principais bactérias encontradas no útero de animais afetados são provavelmente de origem urinária e da região perineal.

A desobstrução da cérvix (piometra aberta ou fechada) constitui uma influência importante na intensidade da doença (BIRCHARD; SHERDING, 2003). Segundo Slatter (1998), se a cérvix encontrar-se aberta, haverá secreção vaginal e os cornos uterinos não permanecerão dilatados. Desta forma a parede do útero pode apresentar-se espessada, com hipertrofia e fibrose do miométrio. Por outro lado, se a cérvix estiver fechada, o útero estará distendido e as paredes uterinas poderão estar delgadas.

Nas piometrites de cérvix fechada, geralmente são verificados acentuados sinais de depressão, letargia, poliúria, polidipsia, vômito, diarreia e possivelmente distensão abdominal (PRETZER, 2008). A fêmea deste relato apresentava distensão abdominal e demonstrou apatia apenas no dia em que veio a óbito. No exame físico da paciente, detectou-se durante a palpação abdominal, o aumento do volume uterino.

Conforme Fossum (2005), a febre é um achado variável e frequentemente encontra-se ausente. Segundo Chen et al. (2007), a temperatura retal em ambas as apresentações desta enfermidade poderá estar normal ou aumentada, em decorrência da infecção uterina. A paciente deste relato apresentou a temperatura retal dentro dos parâmetros considerados normais para a espécie durante o período em que foi monitorada.

Souza et al. (2006) relatam que o hemograma pode auxiliar no diagnóstico da enfermidade, em especial o leucograma, o qual pode apresentar uma leucocitose considerável e característica, mais especificamente, uma neutrofilia. Porém, segundo Feldman (2004), o 
leucograma dos animais com piometra é variável e pode estar dentro dos parâmetros fisiológicos. Durante as quatro semanas em que a cobaia foi monitorada não ocorreram alterações no leucograma, que se manteve dentro dos valores de referência para a espécie (WESCHE, 2009).

A ultrassonografia é o exame diagnóstico mais empregado para esta enfermidade (LIMA, 2009), sendo considerado o exame complementar de eleição para esta afecção (MAGALHÃES et al., 2009). Estudos conduzidos por Tello et al. (1996), demonstraram que este exame foi capaz de detectar $100 \%$ de piometrites em cadelas, sendo todos posteriormente comprovados cirurgicamente. Neste caso, o exame ultrassonográfico foi compatível com os achados post mortem.

O diagnóstico diferencial mais importante para esta patologia é a gestação, pois ambas ocorrem durante a fase luteínica do ciclo estral (VOLPATO et al., 2011), sendo a aparência do útero gravídico e daquele com piometrite, radiograficamente idênticos, até os 40 dias de gestação na cadela (PRETZER, 2008). No entanto, a ultrassonografia abdominal possibilita a distinção da doença ou estado gestacional (GROOTERS, 2003).

Quanto ao tratamento, a OSH é o procedimento cirúrgico indicado para pequenos roedores em uma variedade de circunstâncias, incluindo o controle de tumores mamários e de hipófise, alterações do ovário, como os ovários císticos, piometra, e distocia (BENNETT, 2009; BENNETT; MULLEN, 2003). A realização deste procedimento em roedores de estimação é simples, com potenciais complicações encontradas em qualquer cirurgia, incluindo hemorragia, risco de infecção e deiscência de suturas. No entanto, devido ao pequeno tamanho e natureza do paciente, a anestesia pode ser fatal e isto precisa ser considerado (MIRANDA et al., 2011).

As principais bactérias encontradas no útero de animais com piometra são provavelmente de origem urinária e da região perineal (DE BOSSCHERE et al., 2001). Gomes et al. (2011) e Coggan (2005) verificaram que Escherichia coli é a bactéria mais comumente isolada na infecção uterina de cadelas. Em relação ao exsudato oriundo das piometrites, Ettinger e Feldman (1997) e Fransson et al. (1997), sugerem que este possa ser de constituição variável, de acordo com o agente infectante. Nos casos de infecções por E. coli e Proteus 
spp., o exsudato tende a ser mais viscoso, aderente, de coloração vermelho-amarronzada e odor fétido. Quando a infecção é originada por Streptococcus spp. e Staphylococcus spp., o exsudato apresenta-se purulento (JUBB et al., 1985).

\section{CONCLUSÃO}

Em uma fêmea de porquinho da índia foi realizado o diagnóstico de piometra na forma de cérvix fechada. O animal não apresentou alterações clínicas e hematológicas durante a evolução da doença, o que dificultou o diagnóstico precoce da mesma. As causas que levaram à infecção da paciente não puderam ser esclarecidas devido a não observação prévia do ciclo estral. A causa mortis foi atribuída à ruptura uterina e liberação de exsudato purulento na cavidade abdominal.

\section{PYOMETRA IN A GUINEA PIG (Cavia porcellus)-CASE REPORT}

\section{ABSTRACT}

$\mathrm{P}$ yometra is an inflammation of the uterus, characterized by the accumulation of pus in the uterine lumen associated with a bacterial infection. It can occur in two ways: with open or closed cervix, the latter being considered a veterinary emergency with risk of life for the patient. The treatment of this disease can be surgical, through the of ovariosalpingohysterectomy (OSH) technique, or conservative, but the patient's general condition must always be observed for the correct choice of treatment. The ultrasound is the most widely diagnostic tool used for this disease and is considered the first choice for this condition by several authors. This article aimed to report a case of closed cervix pyometra in a piglet of India (Cavia porcellus). The animal was subjected to the ultrasound examination due to swelling of the abdominal cavity, coming to death during the procedure. Physiological and hematological changes were not observed. Necropsy was conducted and uterine rupture was diagnosed as the cause of death. The release of purulent exudate from the uterus and the uterine horns into the abdominal cavity was observed. It was concluded that the cause of the animal's death was uterine rupture, with extravasation of the uterine contents into the abdominal cavity due to a closed cervix pyometra.

Keywords: Pyometra. Closed cervix. Guinea pig. Uterine infection. 


\section{PIOMETRA EN CONEJILLO DE INDIAS (Cavia porcellus)-REPORTE DE CASO}

\section{RESUMEN}

$\mathrm{P}$ iometra es un proceso inflamatorio del útero que se caracteriza por la acumulación de secreción purulenta en el lumen uterino asociados con una infección bacteriana. Puede presentar en dos formas, con cuello uterino abierto o cerrado, siendo este último considerado una emergencia veterinaria para riesgo de vida para el paciente. Para tratar esta enfermedad puede ser quirúrgico, mediante la técnica de ovariosalpingohisterectomia (SST), o medicamentoso y debiendo siempre evaluarse la condición general del paciente para la correcta elección de tratamiento. La ecografía es la prueba diagnóstica más utilizada para esta enfermedad, siendo considerada la de elección para ésta afección por varios autores. Este artículo tiene como objetivo presentar un caso de piometra de cuello uterino cerrado en un conejillo de indias (Cavia porcellus). El animal fue sometido a examen de ultrasonido debido al aumento de volumen en la cavidad abdominal, muriendo durante el procedimiento. No se observaron cambios fisiológicos y hematológicos. Se procedió a realizar la necropsia y se diagnosticó la ruptura del útero como causa de muerte. Se observó la liberación de exudado purulento desde el útero y los cuernos uterinos en la cavidad abdominal. Se concluyó que la causa de la muerte del animal se debió a la rotura uterina, con la extravasación del contenido uterino en la cavidad abdominal, debido a una piometra en forma de cuello cerrado.

Palabras clave: Piometra. Cuello uterino cerrado. Conejillo de indias. Infección uterina.

\section{REFERÊNCIAS}

BENNETT, R. A. Rodents: soft tissue surgery. In: KEEBLE, E.; MEREDITH, A. (Eds.). Manual of Rodents and Ferrets. Gloucester: BSAVA, 2009. p. 73-85.

BENNETT, R. A. Soft tissue surgery. In: QUESENBERRY, K. E.; CARPENTER, J. W. (Eds.). Ferrets, Rabbits, and Rodents: Clinical Medicine and Surgery. 3. Ed. St. Louis: Elsevier, 2012. p. 327329.

BENNETT, R. A.; MULLEN, H. S. Soft tissue surgery. In: QUESENBERRY, K. E.; CARPENTER, J. W. (Eds.). Ferrets, Rabbits, and Rodents: Clinical Medicine and Surgery. 2. Ed. St. Louis: WB Saunders, 2003. p. 316-328.

BIRCHARD, S. J.; SHERDING, R. G. Manual Saunders: Clínica de Pequenos Animais. 2. ed. São Paulo: Roca, 2003. p. 1115-1118.

BURNS, R. P.; PAUL-MURPHY, J.; SICARD, G. K. Granulosa cell tumor in a guinea pig. Journal of the American Veterinary Medical Association, v. 218, p. 726-728, 2001. 
CHEN, R. F. F.; ADDEO, P. M. D.; SASAKY, A. Y. Piometra aberta em uma cadela de 10 meses. Revista Ciências Agrárias e Ambientais, Curitiba, v. 5, n. 3, p. 317-322, 2007.

COGGAN, J. A. Estudo microbiológico de conteúdo intra-uterino e histopatológico de útero de cadelas com piometra e pesquisa de fatores de virulência em cepas de $E$. coli e o potencial de risco à saúde humana. São Paulo: USP, 2005. Dissertação (Mestrado), Faculdade de Medicina Veterinária e Zootecnia, Universidade de São Paulo, 2005.

DE BOSSCHERE, H.; DUCATELLE, R.; VERMEIRSCH, H.; VAN DEN BROECK, W.; CORYN, M. Cystic endometrial hyperplasia-pyometra complex in the bitch: should the two entitles be disconnected? Theriogenology, v. 55, n. 7, p. 1509-1519, 2001.

ETTINGER, J. S.; FELDMAN, E. C. Tratado de Medicina Interna Veterinária. 4. Ed. São Paulo: Manole, 1997.

EVANGELISTA, L. S. M.; QUESSADA, A. M.; LOPES, R. R. F. B.; ALVES, R. P. A.; GONÇALVES, L. M. F.; DRUMOND, K. O perfil clínico e laboratorial de gatas com piometra antes e após a ovário-histerectomia. Revista Brasileira de Reprodução Animal, Belo Horizonte, v. 35, n. 3, p. 347-351, 2011.

FELDMAN, E. C. O complexo hiperplasia endometrial cística/piometra e infertilidade em cadelas. In: ETTINGER, S. J.; FELDMAN, E. C. (Eds.). Tratado de medicina interna veterinária - Doença do Cão e do Gato. 5. Ed. v. 2, 2004. p. 1632-1649.

FIENI, F. Patologia de los ovaries y el utero. In: WANKE, M. M.; GOBELLO, C. (Eds.). Reproducción en caninos y felinos domesticos. Buenos Aires: Intermédica, 2006. p. 75-89.

FOSSUM, T. W. Cirurgia de pequenos animais. 2. Ed. São Paulo: Roca, 2005. p. 610-672.

FRANSSON, B.; LAGERSTEDT A. S.; HELLMEN, E.; JONSSON, P. Bacteriological findings, blood chemistry profile and plasma endotoxin levels in bitches with pyometra or other uterine disease. Journal Veterinary Medicine, n. 44, p. 417-426, 1997.

GILBERT, R .O. Diagnosis and treatment of pyometra in bitches and Queens. The Compendium on Continuing Education, v. 14, n. 6, p. 777-783, 1992.

GOMES, L. A.; MARTINS, M. I. M; SHIMOZAKA, N.; REIA, A. Z.; FUJIMORI, M.; BARBOSA, C. F.; FERREIRA, C.; MIYASHITA, F. M.; ALMEIDA, W. K. Piometra enfisematosa em cadela. Semina: Ciências Agrárias, Londrina, v. 32, n. 3, p. 1133-1138, 2011.

GROOTERS, A. M. Ovariopatias e uteropatias. In: BIRCHARDS, S. J.; SHERDING, R. G. (Eds.). Manual Saunders: Clínica de Pequenos Animais. 2. Ed. São Paulo: Roca, 2003. p. 1114-1128. 
HAGMAN, R. New aspects of canine pyometra-studies on epidemiology and pathogenesis. Uppsala: SUAS, 2004. 55p. Tese (Doutorado em Clínica de Pequenos Animais), Department of Small Animal Clinical Sciences, Swedish University of Agricultural Sciences, 2004.

JEFFCOATE, I. Fisiología y endocrinología de la reproducción en la perra. In: SIMPSON, G. M.; ENGLAND, G. C. M.; HARVEY, M. J. (Eds.). Manual de reproducción y neonatología en pequeños animales. Reino Unido: BSAVA, 1999. p. 1-14.

JONES, T. C.; HUNT, R. D.; KING N. W. Patologia Veterinária. 6. ed. 2007. 1424p.

JUBB, K. V. F.; KENNEDY, P. C.; PALMER, N. Pathology of domestic animals. 3. Ed. V. 3, San Diego: Academic Press, 1985. p. 305-407.

LIMA, L. R. S. Piometra em Cadelas. São Paulo: FMU, 2009. 53p. Monografia (Graduação), Faculdade de Medicina Veterinária, Faculdades Metropolitanas Unidas, 2009.

MAGALHÃES, F. J. R.; CAMARGO, N. I.; NETO, J. C. M.; COSTA NETO, E. O.; SANTIAGO, T. A.; MANSO FILHO, H. C.; WISCHRAL, A. Piometra e urolitíase vesical em cadela diagnosticada através da ultra-sonografia abdominal; relato de caso. In: JORNADA DE ENSINO, PESQUISA E EXTENSÃO, 9, 2009, Recife. Anais. Recife: UFRP, 2009.

MARKOVITS, J. E.; SAHOTA, P. S. Granular cell lesions in the distal female reproductive tract of aged Sprague-Dawley rats. Veterinary Pathology, v. 37, p. 439-448, 2000.

MIRANDA, J. S.; PARKER, D. L.; BURGESS, H.; WOINAROWICZ, C. Two cases of vaginal bleeding in pet rats. The Canadian Veterinary Journal, v. 52, p. 768-771, 2011.

PRETZER, S. D. Canine presentation of canine piometra and mucometria: a review. Theriogenology, v. 70, n. 3, p. 359-363, 2008.

SCHUETZENHOFER, G.; GOERICKE-PESCH, S.; WEHREND, A. Effects of deslorelin implants on ovarian cysts in guinea pigs. Schweiz Arch Tierheilkd, v. 153, p. 416-417, 2011.

SHI, F.; PETROFF, B. K.; HERATH, C. B.; OZAWA, M.; WATANABE, G.; TAYA, K. Serous cysts are a benign component of the cyclic ovary in the guinea pig with an incidence dependent upon inhibin bioactivity. The Journal of Veterinary Medical Science, v. 64, p. 129-135, 2002.

SLATTER, D. Manual de cirurgia de pequenos animais. 2. Ed. São Paulo: Manole, 1998. p. 1545-1549.

SMITH, F. Canine pyometra. Theriogenology, v. 66, n. 10, p. 610-612, 2006.

SOUZA, J. G. M.; TILLMANN, M. T.; SILVA, P. L. S.; ANTUNES, T. A.; MENDES, T. C. Piometra em animais de companhia: um desafio patológico clínico. In: CONGRESSO DE INICIAÇÃO 
CIENTÍfICA, 15, 2006, Pelotas; ENCONTRO DE PÓS-GRADUAÇÃO, 8, 2006, Pelotas. Anais. Pelotas: UFPEL, 2006.

STORER, T. I.; USINGER, R. L.; STEBBINS, R. C.; NYBAKKEN, J. W. Zoologia geral. São Paulo: Companhia Editora Nacional, 1998. 816p.

TELLO, L.; MARTIN, F.; VALDÉS, A.; ALBALA, A. Estudio comparativo de signos ecográficos, radiográficos y postquirúrgicos em 50 perras com piometra. Archivos de Medicina Veterinária, v. 28, n. 1, p. 137-143, 1996.

VALIM, M. P.; AMORIM, M.; SERRA-FREIRE, N. M. Parasitismo por Acari e Phthiraptera em cobaios [Cavia porcellus (Linnaeus, 1758)] de ambientes rurais e urbanos nos municípios de Silva Jardim e Duque de Caxias, Rio de Janeiro, Brasil. Brazilian Journal of Veterinary Research and Animal Science. São Paulo, v. 41, n. 4, p. 240-246, 2004.

VOLPATO, J. R.; STURION, D. J.; TORRES, Y. M. Tratamento cirúrgico de dois casos de piometra em gatas. In: CONGRESSO DE INICIAÇÃO CIENTÍFICA DAS FACULDADES INTEGRADAS DE OURINHOS, 10, 2011, Ourinhos. Anais. Ourinhos: FIO, 2011.

WEISS, R. R.; CALOMENO, M. A.; SOUSA, R. S.; BRIERSDORF, S. M.; CALOMENO, R. A.; MURADÁS, P. Avaliação Histopatológica, Hormonal e Bacteriológica da Piometra na Cadela. Archives of Veterinary Science, v. 9, n. 2, p. 81-87, 2004.

WESCHE, P. Rodents: clinical pathology. In: KEEBLE, E.; MEREDITH, A. (Eds.). BSAVA Manual of Rodents and Ferrets. Gloucester: BSAVA, 2009. p. 42-46. 